\title{
Cooperative control mechanism and control effect analysis of coal seam backfill mining
}

\author{
Weijian Yu Hunan Province Key Laboratory of Safe Mining Techniques of Coal Mines, China \\ Genshui Wu Hunan University of Science and Technology, China
}

\begin{abstract}
Aiming at the strata movement and control problems caused by coal seam backfill mining, the control mechanism of "backfill + pillar + bearing strata" cooperative support system was proposed based on rock mechanics, surrounding rock control mechanism and related theories. The stability condition of "backfill + pillar+ bearing strata" cooperative support system was then obtained. Considering factors such as the weight of the overlying strata, waste backfill size, goaf size and so on, the concept of equivalent mining height was put forward. The compression value and the formula for analyzing equivalent mining heights for different waste backfill compactness were derived. Finally, along with practical work, theoretical calculations and numerical simulation are used to analyze overlying strata movement law of different waste backfill replacement in the corresponding pillar. The results show that the roof subsidence value and the equivalent mining height caused by secondary strata movement increased with the decrease of compactness degree of waste backfill. When the void ratio is approximately 0.55 , the increment rate of equivalent mining height becomes more sensitive.
\end{abstract}

\section{Introduction}

Currently, a considerable amount of coal remains to be "under three" (under water bodies, buildings, and railways). The mining of such coal mines should not only take into account the recovery of mineral resources but also other issues such as the deformation of surface subsidence and environmental protection.

A number of technologies that have been developed in backfill mining include waste filling, paste filling, highwater material filling, hydraulic filling, comprehensive mechanized filling, and etc. (Miao and Qian, 2009; Zhang et al., 2007; Hema et al., 2003; Liu and Cai, 1998; Zhou et al., 1991; Miao et al., 2010; Yang et al., 2010). Meanwhile, the control mechanism of the strata movement of backfill has also been examined. For example, Karfakis et al. (1996) studied three support mechanisms of rock backfill, namely, the surface support, the local support and the overall support; for the filling material and technology used in the Jinchuan mine, $\mathrm{Yu}$ and Liu (1996) proposed three backfill mechanisms that stress transfer and absorption, isolation mechanism and system interaction. Yu and Wang (2011) analysed the secondary strata movement mechanism and characteristics of backfill mining and found that under the secondary strata, the movement of load-bearing strata is caused by the compression of waste backfill support, deducing parameters such as the secondary stability conditions of "load-bearing strata + waste backfill" carrier, safety factor, width of softening zone under extreme states and the analytical equations of carrying core width; Zhou et al. (2007) applied relevant theories of beams on elastic foundation beam, established a mechanical model for the slate roof beams in paste fill mining, and then expounded a control mechanical mechanism for backfill mining of strata move; Liu et al. (2016) proposed the continuous curved beam theory model for the overlying strata of backfill mining based on a great number of engineering and physics similar test in the backfill mining and identified the 
formation conditions for continuous curved roof beams. Furthermore, characteristics of strata deformation and mechanism of surface subsidence have also been examined (Miao et al., 2012; Zhou et al., 2004; Xu et al., 2007). However, as backfill directly determines the stability of the overlying strata, which play a key support role especially for load-bearing pillar, the analysis of the role of backfill control should simultaneously take full account of synergistic mechanism system of backfill and pillars and overlying strata.

Therefore, it is practically significant to understand the support mechanism and stability conditions of backfill and the guidance of "under three" coal mining so as to reduce ground surface subsidence and environmental harm. Here, relevant theories and methods were adopted to analyse their cooperative support mechanics mechanism and the mechanical properties. In order to control the effect of surface subsidence, relevant mining optimization design schemes were also proposed.

\section{Principle of cooperative support system and stability of strata \\ control in backfill mining}

\subsection{Mechanics principle}

The backfill mining for "under three" coal mines generally leave a number of pillars between the workface and the overlying strata to temporarily provides stability. When the goaf is filled with backfill, the backfill pillar and bearing strata (thick and hard strata, including main roof and the key strata, etc.) have each played a role in supporting the overlying strata, while still interacting with each other and jointly maintaining the overall stability of the overlying strata. This forms a new bearing arch structure known as the "backfill + pillar + bearing strata" cooperative support system. The interaction of the support system is shown in Figure 1. In the support system, backfill not only supports the overlying strata, but also generates lateral pressure to improve the stability of pillars. Thus, the damage of backfill would threaten the stability of pillars, resulting in large deformation and causing great subsidence displacement.

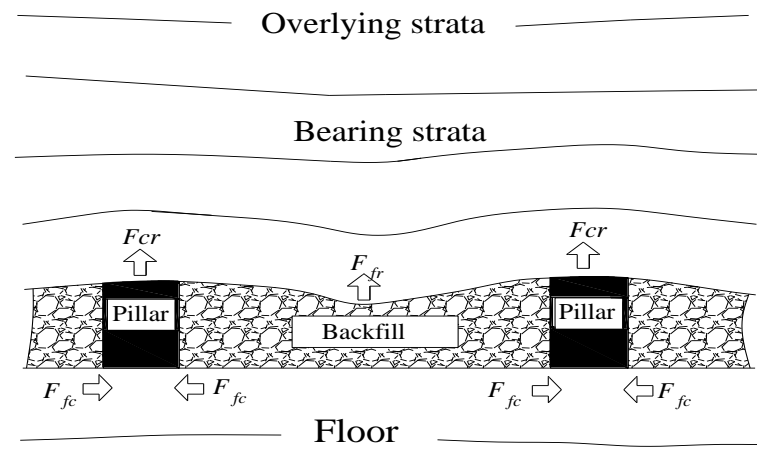

$\mathrm{Ffc}-$ The backfill produces lateral support pressure to pillar; Fcr - The supporting force of pillar to overlying strata; Ffr-The supporting force of backfill to overlying strata

Figure 1 The cooperative support system of "backfill + pillar + bearing strata"

\subsection{Support condition and control mechanism of pillar}

After filling the goaf, the pillar is restored to the triaxial stress state. If the pillar strength is higher or the overlying strata pressure is smaller without causing pillar plastic deformation. Even if the horizontal stress is not applied, pillar can be in a stable state and supports the overlying strata. However, in mining engineering, because of the long intervals between the mining and filling process, partial yield failure occurred in the pillars under the pressure of overlying strata. If backfill generates smaller lateral pressure to support the pillar, under the higher pressure of the overlying strata, the environment of the pillar is still equivalent to a two- 
dimensional stress state. At this time, the pillar only relies on its own strength to support the overlying strata; however, if the lateral pillar expands, large deformation would be uncontrollable, leading to the instability of load-bearing strata. Therefore, the backfill of lateral stress pillar should meet the requirements of a certain value. In order to obtain this lateral stress, according to the Coulomb-Mohr failure criterion, the ultimate strength of the pillar under the triaxial stress state can be expressed as follows:

$$
\sigma_{c t}=\frac{2 c_{c} \cos \varphi_{c}}{1-\sin \varphi_{c}}+\frac{1+\sin \varphi_{c}}{1-\sin \varphi_{c}} \sigma_{c 3}
$$

Where $c_{c}$ is the cohesion of the pillar, $\mathrm{MPa} ; \varphi_{c}$ is the internal friction angle, ${ }^{\circ} ; \sigma_{c 3}$ is the lateral pressure from the backfill, MPa; $\sigma_{c t}$ is the ultimate compressive strength, MPa.

According to Equation (1), the smaller the lateral stress $\sigma_{c 3}$, the smaller the compressive capacity. When $\sigma_{c 3}=0, \sigma_{c 3}$ is uniaxial compressive strength and the supporting capacity of pillar is the least.

Besides, let $\sigma_{c 1}$ be the pillar under the compressive stress of overlying strata and assume that when the pillar is in the limit state under the overlying strata $\left(\sigma_{c 1}=\sigma_{c t}\right)$, the following equation can be obtained:

$$
\sigma_{c 3}=\left(\sigma_{c 1}-\frac{2 c_{c} \cos \varphi_{c}}{1-\sin \varphi_{c}}\right) \frac{1-\sin \varphi_{c}}{1+\sin \varphi_{c}}
$$

Where $\sigma_{c 1}=\sum_{i=0}^{n} \gamma_{i} h_{i}, \gamma_{i}$ is the bulk density of the layer $i, \mathrm{~kg} / \mathrm{m}^{3}$. From bottom to top, the immediate roof $i=1$, with an ascending order; $h_{i}$ is the thickness of layer $i, \mathrm{~m}$.

Therefore, according to the ultimate strength criterion, the stability of the pillar must be ensured to support the overlying strata, and the lateral stress produced by the filling body should meet:

$$
\sigma_{c 3} \geq\left(\sum_{i=0}^{n} \gamma_{i} h_{i}-\frac{2 c_{c} \cos \varphi_{c}}{1-\sin \varphi_{c}}\right) \frac{1-\sin \varphi_{c}}{1+\sin \varphi_{c}}
$$

The above equations are that the pillar can give full play to its own strength and support the stability conditions of the overlying strata, and also is one of the stable conditions cooperative support system of "backfill + pillar + bearing strata".

\subsection{The stability analysis of cooperative support system of "backfill + pillar + bearing strata"}

As shown in Figure 1, the entire range of the sinking bearing strata determines the moving range of the overlying strata. The load-bearing strata is also directly controlled by the backfill and pillar stability. Therefore, the waste filling rate, the backfill compression and pillar may have caused the sinking of the load-bearing strata at any time. It can be seen that bearing strata subsidence mainly consists of goaf filling rate and backfill compression (plastic deformation and compaction of the backfill).

According to the actual filling situation, the goaf filling height of the backfill height ratio is a percentage of the filling rate, namely:

$$
F_{f}=\frac{H_{f}}{H_{c}} \times 100 \%
$$

Where $F_{f}$ is the filling rate, \%; $H_{c}$ is the goaf height, $\mathrm{m} ; H_{f}$ is the filling height of backfill, $\mathrm{m}$.

The height of the unfilled goaf can be obtained as:

$$
H_{n}=\left(1-F_{f}\right) H_{c}
$$

Where $H_{n}$ is the height of unfilled section, $\mathrm{m}$.

In addition, the porosity ratio of backfill is used to express the compactness. Based on soil mechanics, the amount of compression produced by compaction of backfill can be obtained (Xu et al., 2007) as follows: 


$$
S_{1}=\left(\frac{e_{0}-e}{1+e}\right) H_{f}
$$

Where $S_{1}$ is the amount of compression produced by compaction of backfill, $\mathrm{m} ; H_{f}$ is the waste backfill height, $\mathrm{m} ; e_{0}$ is the waste backfill initial void ratio; $e$ is the waste backfill after compaction void ratio.

In addition, according to the characteristics of the backfill mining, the elastic plastic compression transferred from the overlying strata to the filling support can be obtained as follows:

$$
S_{2}=\frac{T}{E_{m}}\left\{\frac{1.5\left[(1-K) b q-\sigma_{c t} r_{p}+2 q r_{p}\right]}{a-2 r_{p}}-\frac{1}{2} \sigma_{c t}\right\}
$$

Where $E_{m}$ is the backfill dynamic elastic modulus, $E_{m}=K_{m} \sqrt{s} E, \mathrm{GPa} ; K_{m}$ is the dynamic modulus; $E$ is the backfill initial modulus, GPa; $s$ is the backfill characteristic parameter value (for the compacted backfill, when the $R M R=23, s=3 \times 10^{-6}$; for the small degree of waste, when the $R M R=3, s=10^{-7}$ ); $T$ is the coal seam thickness $(\mathrm{m})$ and equals $H_{f} ; K$ is the caving coefficient, $K=\frac{h_{c}}{H} h_{c}$ (is the caving height, $\mathrm{m}$; $H$ is the mining depth, $\mathrm{m}) ; q$ is the concentrated load acting on roof strata, $q=\sum_{i=0}^{n} \gamma_{i} h_{i}, \mathrm{MPa} ; b$ is the distance between the midpoints of two pillars, $\mathrm{m} ; r_{p}$ is the maximum softening zone width of pillar under limit state, $m$.

Therefore, the maximum total value of bearing strata subsidence in the roof can be obtained from the analysis above:

$$
\begin{aligned}
S=H_{n}+S_{1}+ & S_{2} \\
& =\left(1-F_{f}\right) H_{c}+\left(\frac{e_{0}-e}{1+e}\right) H_{f}+\frac{T}{E_{m}}\left\{\frac{1.5\left[(1-K) b q-\sigma_{c t} r_{p}+2 q r_{p}\right]}{a-2 r_{p}}-\frac{1}{2} \sigma_{c t}\right\}
\end{aligned}
$$

Because the overlying strata is directly related to stability, its load-bearing strength should be paid special attention to. Meanwhile, with the thick load-bearing strata and hard rocks located in the immediate roof, load-bearing strata is considered as a simply supported beam. Therefore, the subsidence of the rock mass is the deflection of the simply supported beam, that is:

$$
D=\frac{q x}{24 E_{r} I}\left(b^{3}-2 b x^{2}+x^{3}\right)
$$

Where $E_{r}$ is the load-bearing strata elastic modulus, GPa; $I$ is the cross section moment of the loadbearing strata, $\mathrm{m}^{4} ; x$ is the arbitrary distance from the goaf roof to the midpoint of the side pillar, $\mathrm{m}$.

When $x=\frac{b}{2}, S_{1}$ has the maximum value, that is:

$$
D_{\max }=\frac{5 q b^{4}}{384 E_{r} I}
$$

According to strata movement theory and beam principle, the overlying strata subsidence should not exceed the maximum deflection so as to remain stable. Therefore, based on the backfill compression and overlying strata subsidence featuresand joining Equations (8) and (10), the stable condition of the cooperative support system of "backfill + pillar + bearing strata" is obtained as follows:

$$
\frac{5 q b^{4}}{384 E_{r} I} \geq\left(1-F_{f}\right) H_{c}+\left(\frac{e_{0}-e}{1+e}\right) H_{f}+\frac{T}{E_{m}}\left\{\frac{1.5\left[(1-K) b q-\sigma_{c t} r_{p}+2 q r_{p}\right]}{a-2 r_{p}}-\frac{1}{2} \sigma_{c t}\right\}
$$

Equation (11) shows that steady state of the cooperative support system of "filling + pillar + bearing strata" is not only related to a series of factors such as the strength of the load-bearing strata itself, the goaf span, the ultimate strength of the pillar and overlying strata pressure, but is also intimately linked with the compactness and filling rate of the backfill. Therefore, backfill mining should improve not only their ability to support 
bearing strata and pillar but also the compactness and filling rate of backfill, and is of great significance to the control of surface subsidence.

\section{$3 \quad$ Relationship between compaction degree and equivalent mining height of different backfills}

After the waste filling replacement of the whole pillar, the waste sinks and compression occurs under the pressure of mine. The roof then has a new subsidence, which is the secondary strata movement. Here, when the strip mining is carried out, the first subsidence together with the second subsidence of the roof after the waste filling are regarded as the equivalent mining height, namely:

$$
M_{e}=X_{1}+X_{2}
$$

Where $M_{e}$ is the equivalent mining height of the waste filling replacement of the whole pillar; $X_{1}$ is the first roof subsidence of the strip mining; $X_{2}$ is the second roof subsidence after the waste filling.

Therefore, according to Equation (9), it can be obtained that the roof subsidence is the deflection of the simply supported beam at this time, that is:

$$
X_{1}=D=\frac{q x}{24 E_{r} I}\left(b^{3}-2 b x^{2}+x^{3}\right)
$$

Where $E_{r}$ is the roof strata elastic modulus, GPa; $I$ is the roof strata cross section moment, $\mathrm{m}^{4} ; q$ is the concentrated load acting on roof strata, with the value $q=\sum_{i=0}^{n} \gamma_{i} h_{i}, \mathrm{MPa} ; b$ is the width of goaf left by strip mining, $m$.

Similarly, when $x=\frac{b}{2}, X_{1}$ has the following maximum value:

$$
X_{1 \text { max }}=D_{\text {max }}=\frac{5 q b^{4}}{384 E_{r} I}
$$

Furthermore, the total amount of compression consists of that of the waste filling caused by compaction $S_{1}$ and that of waste backfill plastic compaction $S_{2}$. Therefore, there is:

$$
X_{2}=\frac{\left(1+e_{0}\right) \sum_{i=0}^{n} \gamma_{i} h_{i}\left(\frac{b+a}{a}\right)}{H_{f}\left(1+e_{\min }\right)\left(\sigma_{3} \frac{1+\sin \varphi}{1-\sin \varphi}+2 c \frac{\cos \varphi}{1-\sin \varphi}\right)}+\frac{T}{E_{m}}\left\{\frac{1.5\left[(1-K) b q-\sigma_{z l} r_{p}+2 q r_{p}\right]}{a-2 r_{p}}-\frac{1}{2} \sigma_{z l}\right\}
$$

Finally, the analytical equation of mining height can be obtained:

$$
\begin{aligned}
M_{e}=\frac{q x}{24 E I}\left(b^{3}\right. & \left.-2 b x^{2}+x^{3}\right)+\frac{\left(1+e_{0}\right) \sum_{i=0}^{n} \gamma_{i} h_{i}\left(\frac{b+a}{a}\right)}{H_{f}\left(1+e_{\min }\right)\left(\sigma_{3} \frac{1+\sin \varphi}{1-\sin \varphi}+2 c \frac{\cos \varphi}{1-\sin \varphi}\right)} \\
+ & \frac{T}{E_{m}}\left\{\frac{1.5\left[(1-K) b q-\sigma_{z l} r_{p}+2 q r_{p}\right]}{a-2 r_{p}}-\frac{1}{2} \sigma_{z l}\right\}
\end{aligned}
$$

\section{$4 \quad$ Case analysis and numerical calculation}

\subsection{Basic mechanical data}

Zhouyuanshan coal mine has a coal seam depth of $300 \mathrm{~m}$ and a thickness of $5 \mathrm{~m}$ and the mechanical parameters of the strata and the backfill are shown in Table 1. The initial coal seam adopted with strip mining has a mining width (i.e.: the width $b$ of goaf) of $30 \mathrm{~m}$ and the remaining pillar width (i.e.: waste backfill support width a) of $30 \mathrm{~m}$. A layer of hard rock mass which is medium sandstone (No. 4) exists in the roof strata and is 
plays a key strata role in layers.

Table 1 Mechanical parameters of strata

\begin{tabular}{|c|c|c|c|c|c|c|c|c|c|}
\hline & $\begin{array}{l}\text { Surrounding } \\
\text { rock ( } \\
\text { From top to } \\
\text { bottom) }\end{array}$ & $\begin{array}{c}\text { Strata } \\
\text { thickness } \\
(h / m)\end{array}$ & $\begin{array}{c}\text { Bulk } \\
\text { density } \\
\left(y / \mathrm{g} \mathrm{cm}^{-3}\right)\end{array}$ & $\begin{array}{l}\text { Uniaxial compressive } \\
\text { strength }(R / \mathrm{MPa})\end{array}$ & $\begin{array}{c}\text { Uniaxial tensile } \\
\text { strength } \\
\text { (Rt/MPa) }\end{array}$ & $\begin{array}{l}\text { Cohesion } \\
\text { (C/MPa) }\end{array}$ & $\begin{array}{c}\text { Internal } \\
\text { friction angle } \\
\left(\Phi /{ }^{\circ}\right)\end{array}$ & $\begin{array}{l}\text { Elastic } \\
\text { modulus } \\
\text { (E/GPa) }\end{array}$ & $\begin{array}{c}\text { Poisson } \\
\text { ratio } \\
\mu\end{array}$ \\
\hline 1 & $\begin{array}{l}\text { Overlying } \\
\text { strata }\end{array}$ & & 2.2 & 24 & 1.6 & 2.3 & 25 & 1.26 & 0.23 \\
\hline 2 & $\begin{array}{c}\text { Fine } \\
\text { sandstone }\end{array}$ & 15 & 2.54 & 65 & 1.03 & 3.21 & 26 & 1.42 & 0.21 \\
\hline 3 & Siltstone & 15 & 2.64 & 40 & 1.80 & 4.25 & 32 & 1.65 & 0.29 \\
\hline 4 & $\begin{array}{l}\text { Medium } \\
\text { sandstone }\end{array}$ & 10 & 2.4 & 36 & 2.91 & 3.31 & 31 & 1.24 & 0.24 \\
\hline 5 & Mudstone & 10 & 2.3 & 14 & 1.12 & 3.21 & 20 & 0.38 & 0.25 \\
\hline 6 & $\begin{array}{l}\text { Sandy } \\
\text { mudstone }\end{array}$ & 5 & 2.5 & 18 & 1.81 & 2.70 & 26 & 1.05 & 0.22 \\
\hline 7 & Coal seam & 5 & 1.6 & 12 & 1.43 & 1.50 & 18 & 0.45 & 0.19 \\
\hline 8 & $\begin{array}{l}\text { Sandy } \\
\text { mudstone }\end{array}$ & 10 & 2.5 & 18 & 1.81 & 2.70 & 26 & 1.05 & 0.22 \\
\hline
\end{tabular}

The compaction degree of waste, characterized by the density of the compacted condition, is a key indicator for the quality testing of the replacement of whole "under three" pillars by waste filling construction quality testing. The greater degree of compaction and the greater the density, the better the overall performance of the filling material. Therefore, in order to investigate different waste backfill mining to substitute "under three" pillars, the research takes into account the different degree of compaction of waste backfill. The compaction degree of waste is the percentage of waste under external forces when it reaches the maximum dry density that can be achieved in the indoor standard compaction test, calculated by the actual dry density of the underground filling. According to the experimental and numerical analysis, the compaction degree of waste backfill could reach 1 , as shown in Table 2 . The parameters of the compacted waste backfill less than 1 decrease, with the reduction of their coefficient values corresponding with the compaction degree of waste backfill. The mechanical strength parameters of the waste backfill with compactness of $0.4,0.5,0.6,0.8$, and 0.9 are shown in Table 2 . In addition, it is assumed that waste backfill maximum initial void ratio $e_{\max }$ is 0.9 andthe minimum porosity after compaction void ratio $e_{\min }$ is 0.4 . The calucation results according to the equation $D_{r}=\left(e_{\max }-e_{0}\right) /\left(e_{\max }-e_{\min }\right)$ corresponding to the different density of the initial void ratio, are shown in Table 2.

Table 2 Mechanical parameters of waste backfill with different compaction degree

\begin{tabular}{|c|c|c|c|c|c|c|c|c|c|}
\hline Number & $\begin{array}{c}\text { Compactness } \\
D_{r}\end{array}$ & $\begin{array}{c}\text { Initial void } \\
\text { ratio } \\
e_{0}\end{array}$ & $\begin{array}{c}\text { Bulk } \\
\text { density } \\
\left(y / \mathrm{g} \mathrm{cm}^{-3}\right)\end{array}$ & $\begin{array}{c}\text { Compressive } \\
\text { strength } \\
(R / \mathrm{MPa})\end{array}$ & $\begin{array}{c}\text { Tensile } \\
\text { strength } \\
\left(R_{\mathrm{t}} / \mathrm{MPa}\right)\end{array}$ & $\begin{array}{c}\text { Cohesion } \\
\text { (C/MPa) }\end{array}$ & $\begin{array}{c}\text { Internal } \\
\text { friction angle } \\
\left(\Phi /^{\circ}\right)\end{array}$ & $\begin{array}{c}\text { Elastic } \\
\text { modulus } \\
(E / G P a)\end{array}$ & $\begin{array}{c}\text { Poisson } \\
\text { ratio } \\
\mu\end{array}$ \\
\hline 1 & 1 & 0.4 & 2.1 & 21 & 0.61 & 0.8 & 34 & 0.41 & 0.21 \\
\hline 2 & 0.9 & 0.45 & 1.89 & 18.9 & 0.549 & 0.72 & 30.6 & 0.369 & 0.23 \\
\hline 3 & 0.8 & 0.5 & 1.68 & 16.8 & 0.488 & 0.64 & 27.2 & 0.328 & 0.26 \\
\hline 4 & 0.7 & 0.55 & 1.47 & 14.7 & 0.427 & 0.56 & 23.8 & 0.287 & 0.30 \\
\hline 5 & 0.6 & 0.6 & 1.26 & 12.6 & 0.366 & 0.48 & 20.4 & 0.246 & 0.35 \\
\hline 6 & 0.5 & 0.65 & 1.05 & 10.5 & 0.305 & 0.4 & 17 & 0.205 & 0.42 \\
\hline 7 & 0.4 & 0.7 & 0.84 & 8.4 & 0.244 & 0.32 & 13.6 & 0.164 & 0.49 \\
\hline
\end{tabular}

\subsection{Numerical calculation and comparative analysis}

In this research, FLAC 2D software was used for numerical calculation. A two-dimensional model was 
established based on the various parameters of strata mechanics. The specific size for the model is 410 (Xaxis direction: coal seam strike) by 400 (Y-axis direction: strata height); the boundary conditions for the model is as follows: displacement boundary is used for the front, back and lower boundary. As the upper boundary is below the ground surface, a stress of $\gamma \mathrm{H}=5.635 \mathrm{MPa}$ needs to be imposed, where $\mathrm{H}$ is $245 \mathrm{~m}$, the average value $\gamma$ is $2.3 \mathrm{~g} / \mathrm{cm}^{3}$. Overall by the FLAC $2 \mathrm{D}$ model established in Figure 2(a), the mesh size is $164 \times 160$. The calculation follows the process of "initial stress balance $\rightarrow$ strip mining $\rightarrow$ the calculation of first strata movement $\rightarrow$ the waste filling replacement whole pillar $\rightarrow$ the calculation of second strata movement". The monitoring the whole process of unbalanced force is shown in Figure 2(b), which represents the whole strip mining and the replacement process of waste filling.

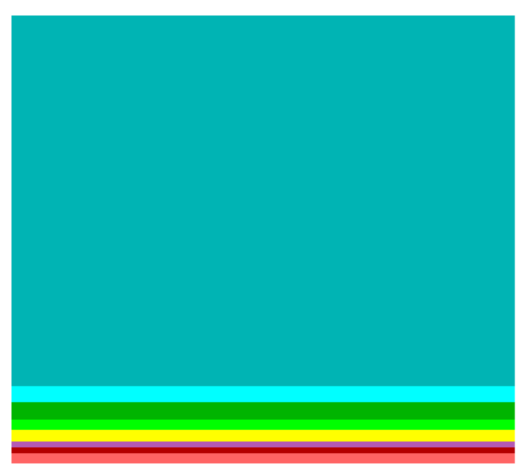

(a)

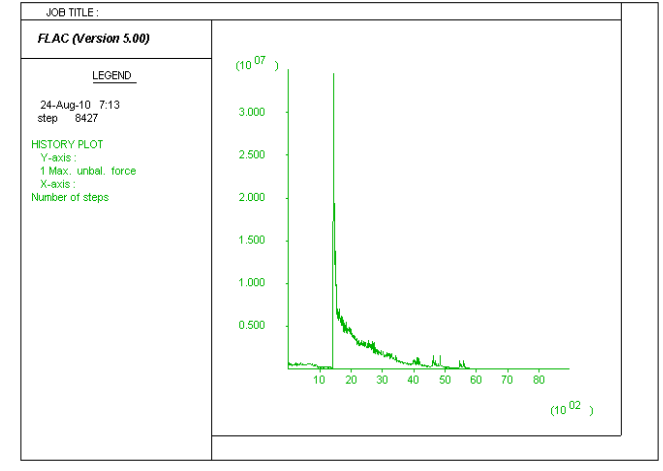

(b)

Figure 2 Calculation model and process; (a) two-dimensional model; (b) unbalanced force monitoring curve

After calculating the stress balance, in order to accord with the theoretical subsidence values of the first strip mining roof, iteration is performed for the corresponding steps. Ultimately, the first subsidence value of the roof is $0.6584 \mathrm{~m}$, shown in Figure 3. In terms of the overlying strata movement, with a continuous displacement caused by strip mining, roof subsidence comply with the general characteristics of loose zone, meaning that the closer the goaf, the greater amount of displacement, and pillar was in a compressed state. After the stress is released, the pillar is subjected to horizontal stress, creating a greater horizontal displacement at the same time, especially at both sides of the pillar. After carrying out strip mining, the goaf roof overlying strata stress will be released to a certain extent, and a considerable part of the stress is transferred to the pillar, with the number of pillars under stress increasing. Horizontal stress and vertical stress of the pillar contours were in the saddle distribution, but the growth trend of both is the opposite. That is, the horizontal stress of the pillar first increases and then decreases from floor to roof, while the vertical stress has been reduced, and on both sides of the coal pillar occurred vertical stress disruption concentration, which has the maximum value. 


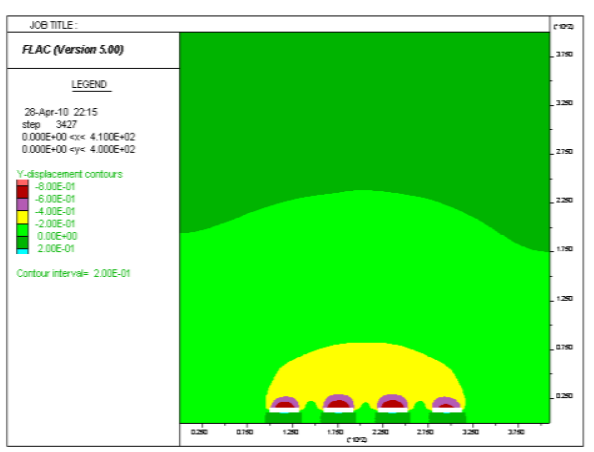

(a)

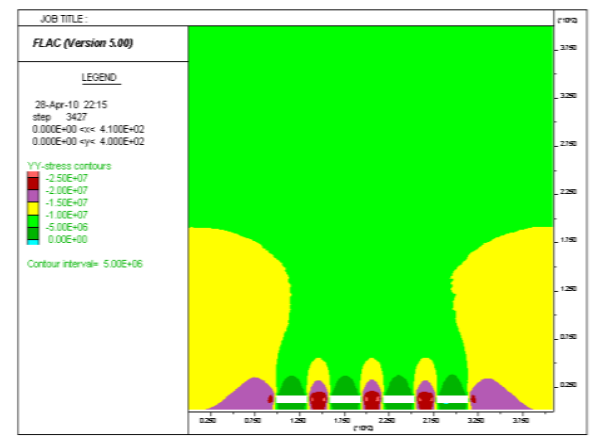

(c)

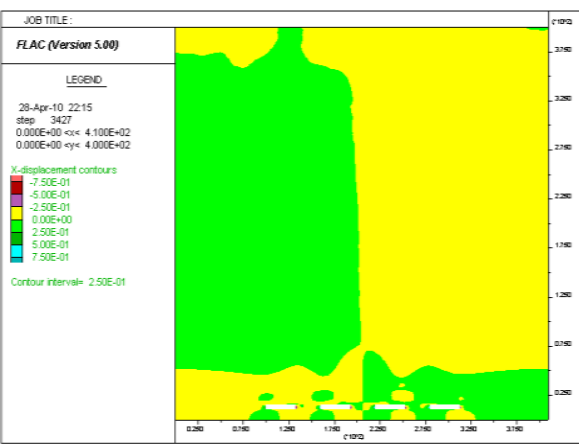

(b)

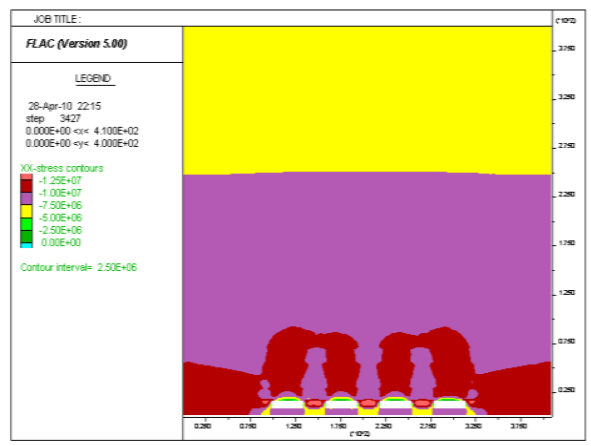

(d)

Figure 3 Calculation results of the first strata movement caused by strip mining; (a) Subsidence equivalent graph; (b) Horizontal displacement equivalent graph; (c) Horizontal stress equivalent graph; (d) Vertical stress equivalent graph

After calculating the resulting waste filling replacement of overall pillar displacement, part of the stress results are shown in Figure 4 due to the limited space. As can be seen from the figure, the closer the goaf, the greater displacement of strata subsidence. The subsidence displacement of strata is relatively small when supported by the waste backfill. In addition, after the waste replacement of the pillar, the stress of the overlying strata in the goaf roof is further released, and waste backfill features higher stress level and concentration, and the vertical stress continues to show a contours saddle distribution.

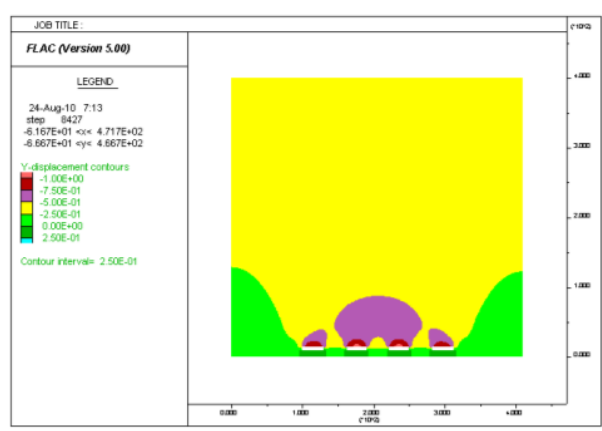

(a)

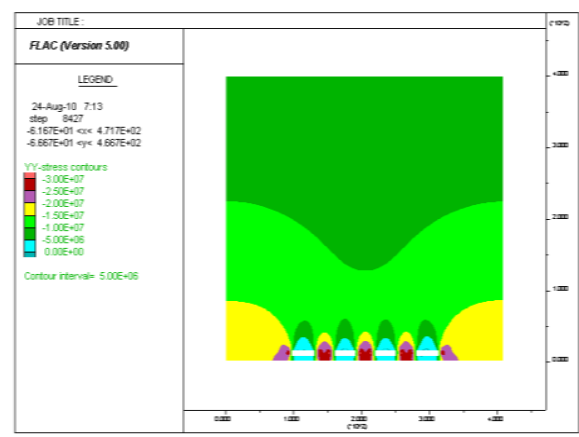

(b)

Figure 4 Calculation results of the first strata movement caused by strip mining after waste filling replacement of overall pillar; (a) Subsidence equivalent graph; (b) Vertical stress equivalent graph 
Table 3 Calculation results of strata movement with different waste backfill

\begin{tabular}{ccccccccc}
\hline Number & $\begin{array}{c}\text { Compactness } \\
\boldsymbol{D}_{r}\end{array}$ & $\begin{array}{c}\text { Roof second } \\
\text { subsidence } \\
\text { maximum } \\
\text { value } \\
\left(\boldsymbol{S}_{2} / \mathrm{m}\right)\end{array}$ & $\begin{array}{c}\text { Equivalent } \\
\text { mining } \\
\text { height } \\
(\mathbf{M} / \mathbf{m})\end{array}$ & $\begin{array}{c}\text { Backfill } \\
\text { maximum lateral vertical stress } \\
\text { displacement } \\
\left(\boldsymbol{D}_{\text {max }} / \mathrm{m}\right)\end{array}$ & $\begin{array}{c}\text { Maximum } \\
\text { of backfill } \\
\left(\sigma_{\max } / \mathrm{MPa}\right)\end{array}$ & $\begin{array}{c}\text { Softening } \\
\text { zone of } \\
\text { backfill } \\
\text { range } \\
\left(\boldsymbol{R}_{p} / \mathrm{m}\right)\end{array}$ & $\begin{array}{c}\text { Overlying } \\
\text { strata } \\
\text { influence } \\
\text { height } \\
(\boldsymbol{H} / \mathbf{m})\end{array}$ & $\begin{array}{c}\text { Safety } \\
\text { factor } \\
\boldsymbol{F}\end{array}$ \\
\hline 1 & 1 & 0.4436 & 1.102 & 0.8254 & 19.012 & 18.980 & 46.018 & 1.68 \\
2 & 0.9 & 0.4536 & 1.112 & 0.8253 & 19.051 & 18.980 & 48.772 & 1.64 \\
3 & 0.8 & 0.4746 & 1.133 & 0.8252 & 19.610 & 18.990 & 52.710 & 1.63 \\
4 & 0.7 & 0.5566 & 1.215 & 0.9251 & 20.000 & 20.990 & 62.000 & 1.57 \\
5 & 0.6 & 0.8066 & 1.465 & 1.2258 & 18.058 & 28.546 & 72.548 & 1.52 \\
6 & 0.5 & 1.1926 & 1.851 & 1.8041 & 19.700 & 30.000 & 83.420 & 1.43 \\
7 & 0.4 & 1.7656 & 2.424 & 2.5010 & 19.501 & 30.000 & $>100$ & 1.33 \\
\hline
\end{tabular}

In addition, Table 3 shows the different second subsidence values caused by waste backfills of different compaction degrees, the equivalent mining height, the maximum deformation and stress results inside the backfill. As can be seen from the results, the secondary movement of roof strata subsidence and equivalent mining height value are constantly increasing with the decrease of the compaction degree of the backfill, showing a linear relationship between the two. By the theoretical calculation between the initial void ratio $e_{0}$ and equivalent mining height $M_{e}$ curve and through the numerical analysis, the results between initial void ratio $e_{0}$ and equivalent mining height $M_{e}$ curves are shown in Figure 5, showing a relatively good agreement between the theoretical results and numerical analysis, except when the void ratio is about 0.55 , the growth rate of equivalent mining height $M_{e}$ obtained by numerical results is more sensitive. It could be interpreted as when the pore volume of waste filling material is much larger than that of the material particles, the compression of waste backfill has a larger value. Especially in the initial filling stage, due to the looser waste backfill and small roof support force, large subsidence displacements will occur in the roof. If the subsidence displacement reaches a certain value, the overlying strata may have accelerated sinking or even get broken, inevitably leading to higher acceleration of equivalent mining height.

Furthermore, the maximum lateral displacement $D_{\max }$ of the backfill is increasing with the increase of void ratio $e_{0}$ When the void ratio $e_{0}$ reaches 0.55 , the increase of the maximum lateral displacement $D_{\max }$ is significantly faster, which is also related to the roof subsidence and the longitudinal compression of the backfill. Meanwhile, when backfill longitudinal compression gradually increases, the side of backfill will produce compression, and then it will cause a transverse volume expansion and create a greater lateral displacement. The sudden acceleration of the compression and deformation speed of the backfill results in a sharp increase of lateral stress and lateral displacement.

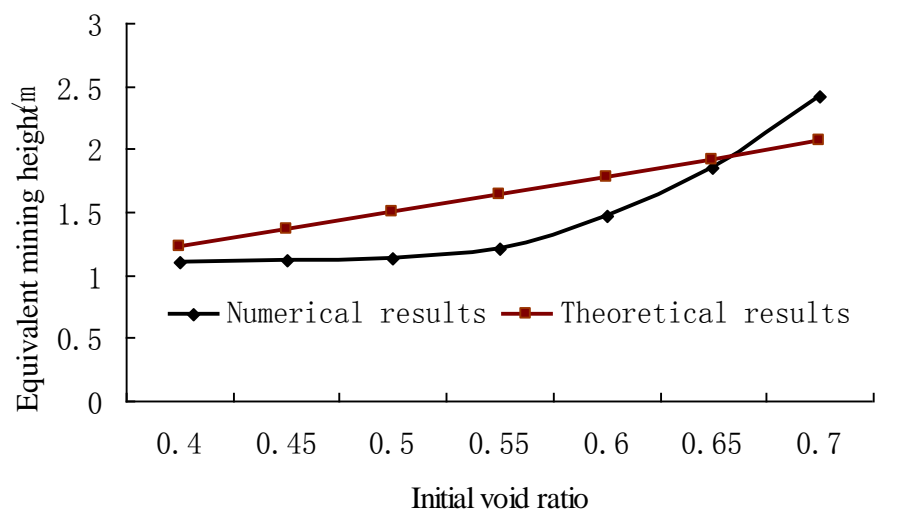

Figure 5 The relationship between initial void ratio $e_{0}$ and equivalent mining height $M_{e}$ 


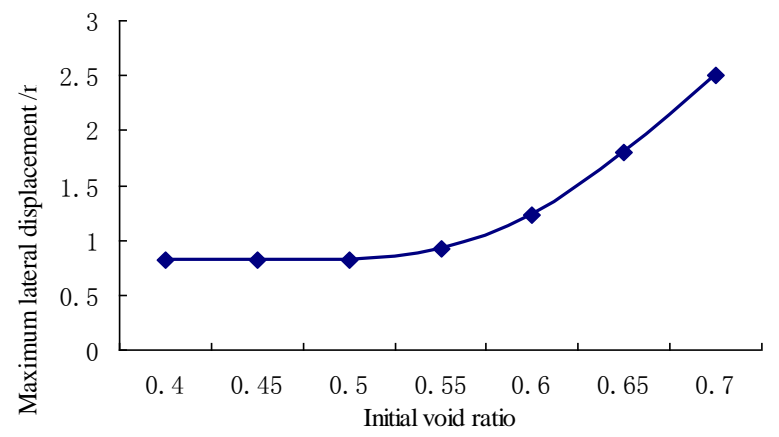

Figure 6 The relationship between initial ratio $e_{0}$ and maximum lateral displacement $D_{\max }$

\subsection{The movement law of overlying strata caused by different waste backfill}

Figure 7 illustrates the relationship between backfill void ratio $e_{0}$ and the maximum vertical stress $\sigma_{\max }$, after the replacement of "under three" pillar by waste backfill. As can be seen, the maximum vertical stress $\sigma_{\max }$ and void ratio $e_{0}$ is not entirely linear. When the void ratio $e_{0}$ features a small value, the maximum vertical stress $\sigma_{\max }$ increased with void ratio $e_{0}$, reaching a maximum value at 0.55 (20 MPa); when the void ratio $e_{0}$ is between 0.55 and 0.65 , the maximum vertical stress $\sigma_{\max }$ decreases first and then increases, equal to 0.6 at the minimum value $(18.058 \mathrm{MPa})$; it then slowly decreases after 0.65 . This vertical stress variation law shows a changing effect of overlying strata pressure on backfill, in which the increase of the void ratio $e_{0}$ results in both the increase and decrease of pressure. When the void ratio $e_{0}$ is less than 0.55 , the roof subsidence value and the backfill amount of compression are increasing with the void ratio. Meanwhile, the overlying strata stays intact and has a certain carrying capacity. But the strata pressure was gradually transferred to the filling support body, causing the gradual increase of the maximum vertical stress. When the void ratio $e_{0}$ is between 0.55 and 0.6 , because of the loose waste backfill, the support effect of the overlying strata is very small and the roof subsidence value and the backfill amount of compression are very large, with a certain degree of loose and falling in the broken overlying strata and the roof . Finally, the stress is partially released, weakening the role of stress in filling support body. When the void ratio $e_{0}$ is larger than 0.6 , overlying strata falling has occurred, with the goaf full of broken rock, and the overlying strata moves slowly in a steady state. Meanwhile, the pressure of overlying strata is gradually transferred to the waste backfill and the maximum vertical stress gradually becomes larger and then stabilizes.

The numerical simulation results of the overlying strata movement law caused by the replacement of the "under three" pillar with different compacted waste backfills are shown in Figure 8. Obviously, between 1 to 0.7 degree of compaction, the subsidence movement of roof strata is relatively close to waste backfill subsidence value, indicating the better control of waste backfill towards back strata movement in the period. While the degree of compaction is less than 0.7 , the roof strata subsidence value is comparatively larger and rapidly increases in a linear way, meaning a poor control of strata movement. In addition, as Table 3 above shows, the calculation results of the backfill softening zone range $R_{p}$, overlying strata influence height $H$ and the safety factor $F$ value indicates that the smaller degree of compaction $D_{r}$, the higher the degree of damage of the backfill and overlying strata, and the smaller the safety factor (when safety factor is less than 1.5 , the long-term stability of waste backfill cannot be guaranteed). Thus, in the "under three" pillar backfill mining, improving the waste degree of compaction is key to controlling surface subsidence. 


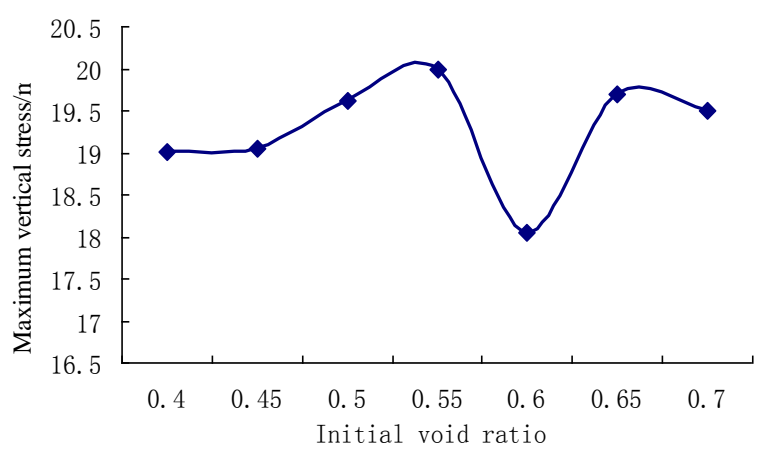

Figure 7 The relationship between void ratio $e_{0}$ and maximum vertical stress $\sigma_{\max }$

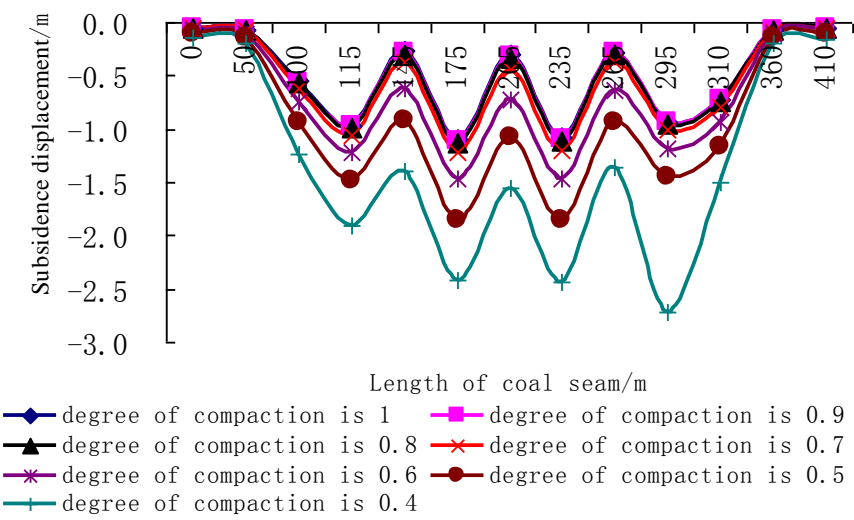

Figure 8 The movement law of roof strata caused by different void ratio $e_{0}$

\section{$5 \quad$ Conclusions}

According to the above theoretical analysis and numerical calculations, the following conclusions can be drawn:

- In the "under three" coal filling mining, the backfill, load-bearing strata and pillar interact with one other to form a new community bearing structure, referred to as "backfill + pillar + bearing strata" cooperative support system. On the one hand, the backfill produced coal pillar lateral stress, suppressed the further swelling of deformation in pillar and played a significant role in reinforcing pillars; On the other hand, the force generated by backfill supports the overlying strata, having suppressed the subsidence displacement of increasing overlying strata, hence avoiding the strata collapse.

- In order to stabilize the "backfill + pillar + bearing strata" cooperative support system, backfill of the pillar lateral stress should meet certain requirements. The compactness and filling rate of backfill are two factors that can regulate the relationships influencing the overlying strata subsidence. The greater the compactness and the filling rate, the greater the limiting force on the lateral expansion of the pillar, serving to maintain the intactness of pillar. In addition, it is more reasonable to adjust the stress distribution law of overlying strata at the same time, so that the original stress concentration is greatly reduced, which is beneficial to improving the stress environment of pillar.

- The numerical calculation show that the roof subsidence and the equivalent mining height of secondary strata movement steadily increased with the decrease of compactness degree of waste backfill. The numerical results show that when the void ratio is about 0.55 , the increment speed of equivalent mining height $M_{e}$ becomes more sensitive. However, the theoretical results and 
numerical results are relatively similar.

- The maximum vertical stress and void ratio has a non-linear relationship. When the void ratio $e_{0}$ features a smaller value, the maximum vertical stress increases with the increases of void ratio, reaching a maximum value of $0.55(20 \mathrm{MPa})$. When the void ratio $e_{0}$ is between 0.55 and 0.65 , the maximum vertical stress first decreased and then increased, until it reaches the minimum value $(18.058 \mathrm{MPa})$ at $0.6 \mathrm{~h}$ and then slowly decreases after 0.65 .

- With regard to the degree of compaction between 1 to 0.7 , the subsidence of roof strata caused by a variety of "under three" pillar replacement by waste backfill is close to the waste backfill subsidence value. When the degree of compaction is less than 0.7 , a large difference exists between the subsidence of roof strata and waste backfill subsidence value and features a linear growth. The smaller waste backfill compaction degree of the replacement of "under three" pillar, the higher damage degree of the backfill and overlying strata and the smaller safety factor, and longer-term stability of the "bearing strata + waste backfill" cannot be ensured.

\section{Acknowledgements}

This work was supported by the National Natural Science Foundation of China (51574122), the Open Research Foundation of Key Laboratory of Safety and High-efficiency Coal Mining, Ministry of Education (Anhui University of Science and Technology) (JYBSYS2015201) and Scientific Research Fund of Hunan Provincial Education Department (14A045).

\section{References}

Karfakis, M.G., Bowman, C.H. and Topuz, E. 1996, 'Characterization of coal-mine refuse as backfilling material', Geotechnical and Geological Engineering, vol. 14, no. 2, pp. 129-150.

Liu, J.G., Zhao, J.W., Li, M.M. and Zuo, J.P. 2016, 'Continuous curved beam formation and strata control theory in coal backfill mining', Journal of China Coal Society, vol. 41, no. 2, pp. 383-391.

Liu, T.Y. and Cai, S.J. 1998, 'Status quo of application and research of paste fill technology in China and abroad', China Mining Magazine, vol. 7, no. 5, pp. 1-4.

Miao, X.X. and Qian, M.G. 2009, 'Research on green mining of coal resources in China: current status and future prospects', Journal of Mining\& Safety Engineering, vol. 26, no. 1, pp. 1-14.

Miao, X.X., Huang, Y.L., Ju, F., Mao, X.B. and Guo, G.L. 2012, 'Strata movement theory of dense backfilling mining', Journal of China University of Mining \& Technology, vol. 41, no. 6, pp. 863-867.

Miao, X.X., Zhang, J.X. and Guo, G.L. 2010, 'Study of waste-filling method and technology in fully-mechanized coal mining', Journal of China Coal Society, vol. 35, no. 1, pp. 1-6.

Siriwardane, H.J., Kaman, R.S.S. and Ziemkiewicz, P.F. 2003, 'Use of waste materials for control of acid mine drainage and subsidence', Journal of Environmental Engineering, vol. 129, no. 10, pp. 910-915.

Sun, X.G., Zhou, H.Q. and Wang G.W. 2007, 'Digital simulation of strata control by solid waste paste-like body for backfilling', Journal of Mining \& Safety Engineering, vol. 24, no. 1, pp. 117-126.

Xu, J.L., You Q., Zhu, W.B., Li, X.S. and Lai W.Q. 2007, 'Theorectical study of strip filling to control mining subsidence', Journal of China Coal Society, vol. 32, no. 2, pp. 119-122.

Yang, J.W., Yu, W.J. and Gao, Q. 2010, 'Optimization and practice of mechanized panel cutting and filing mining method in no.2 mine district, jinchuan mine', Mineral Engineering Research, vol. 25, no. 3, pp. 11-15.

Yu, W.J. and Wang, W.J. 2011, 'Strata movement induced by coal-pillar under three circumstances exchanged by waste backfill and 
quadratic stability law', Chinese Journal of Rock Mechanics and Engineering, vol. 30, no. 1, pp. 105-112.

Yu, X.F. and Liu, T.Y. 1996, 'The filling mechanism and mining theory in Jinchuan', The 4th academic meeting symposium, Chinese Society for Rock Mechanics and Engineering.

Zhang, J.X., Miao, X.X., Mao, X.B. and Chen, Z.W. 2007, 'Research onwaste substitution extraction of strip extraction coal-pillarmining', Chinese Journal of Rock Mechanics and Engineering, vol. 26, no. S1, pp. 2687-2693.

Zhou, H.Q., Hou, C.J. and Yi, H.W. 1991, 'Research and application of the roadside backfilling technique with high water content materials in China and abroad'. Ground Pressure and Strata Control, vol. 8, no. 4, pp. 2-6.

Zhou, H.Q., Hou, C.J., Sun, X.K., Qu, Q. and Chen, D.J. 2004, 'Solid waste paste filling for none-village-relocation coal mining', Journal of China University of Mining \& Technology, vol. 33, no. 2, pp. 154-158. 